\title{
Nature in virtual reality improves mood and reduces stress: evidence from young adults and senior citizens
}

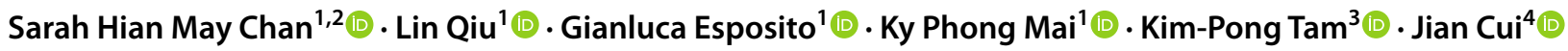

Received: 21 January 2021 / Accepted: 2 November 2021

(c) The Author(s), under exclusive licence to Springer-Verlag London Ltd., part of Springer Nature 2021

\begin{abstract}
Large populations worldwide have been deprived from nature experiences due to mass quarantines and lockdowns during the COVID-19 pandemic, and face a looming mental health crisis. Virtual reality offers a safe and practical solution to increase nature exposure. This research examined the effects of virtual nature using a within-subject design with young adults (Study 1) and senior citizens (Study 2). Results from the young adult sample showed that walking in a virtual forest reduced negative affect due to enhanced nature connectedness, and reduced stress measured by heart rate. Consistently, the senior citizen sample reported improved positive affect due to enhanced nature connectedness after the virtual nature walk. Our findings unveil the underlying mechanism of how virtual nature may improve psychological well-being and demonstrated how virtual nature can be used as an intervention to promote mental health.
\end{abstract}

Keywords Virtual reality $\cdot$ Nature $\cdot$ Emotion $\cdot$ Stress $\cdot$ Well-being $\cdot$ Mental health

\section{Introduction}

As the world grapples with the COVID-19 public health emergency, a mental health crisis is emerging (The Lancet Infectious Diseases 2020). Increased rates of psychological distress have been reported worldwide, including Italy (Moccia et al. 2020), China (Li et al. 2020), New Zealand (Sibley et al. 2020), South Korea (Lee et al. 2021), France (Bourdillon et al. 2020), and UK (White and Van Der Boor 2020). While mass quarantines and social distancing policies have shown success in containing the virus (Kharroubi and Saleh 2020; Tang et al. 2020), they have also reduced nature exposure by limiting residents' access to parks and green space (Slater et al. 2020). Responses from over 5000 people from nine different countries show that reduced nature exposure

Lin Qiu

linqiu@ntu.edu.sg

1 Division of Psychology, School of Social Sciences, Nanyang Technological University, Singapore, Singapore

2 Global Asia, Interdisciplinary Graduate School, Nanyang Technological University, Singapore, Singapore

3 Division of Social Science, The Hong Kong University of Science and Technology, Clear Water Bay, Kowloon, Hong Kong

4 Nanyang Technological University, Singapore, Singapore was related to increased likelihood of experiencing anxiety and depression during lockdowns (Pouso et al. 2021). This calls for novel means to increase nature exposure and promote mental health during the pandemic.

Virtual reality (VR) has shown to be an effective tool to address mental health issues like depression, pain, stress and phobias (Matamala-Gomez et al. 2021; Park et al. 2019; Robillard et al. 2003). Through VR, users can be immersed in a virtual environment and experience the sense of actually being there (Slater 2018). Being in a virtual natural environment enables relaxation and enhances resistance to stress which can alleviate symptoms of anxiety and depression (Liszio and Masuch 2019; White et al. 2018). Scholars have proposed to use natural environments in VR to alleviate symptoms of anxiety and depression (White et al. 2018), and promote relaxation to overcome the psychological burden of the Coronavirus (Riva et al. 2020).

Recently, VR technologies have become increasingly affordable and widely adopted. VR is particularly attractive to young people because of its cutting-edge technology and immersive experiences (Rogers 2018). The popular VR gaming platform Steam reported 2.9 million monthly connected VR users in April 2021, representing a 110\% yearon-year increase (Lang 2021). Seniors can also successfully use VR (Cherniack 2011; Huygelier et al. 2019; Kothgassner et al. 2018), and have been found to benefit from vestibular 
rehabilitation (Micarelli et al. 2019) and memory training (Optale et al. 2010) through head-mounted immersive VR. Given that seniors often face safety and mobility barriers to visit natural environments (Satariano et al. 2012; Wen et al. 2018), and that these concerns are exacerbated during the pandemic due to their bio-psychosocial vulnerabilities (Banerjee 2020), they are in strong need of a safe alternative method for accessing nature.

Based on the above-commented literature about the potential of using VR to provide nature exposure, this study seeks to investigate if virtual natural environments can promote mental health by improving mood and reducing stress. We conducted two studies, one with young adults and one with senior citizens. We collected both self-report and physiological data, and found beneficial effects of virtual nature across both samples. Our findings provide strong empirical evidence that supports the use of virtual natural environments to promote mental health.

\subsection{Effects of nature exposure on emotional well-being}

Research on the psychological effects of nature exposure has largely stemmed from the biophilia hypothesis (Kellert and Wilson 1993; Wilson 1984), stress recovery theory (SRT; Ulrich 1983; Ulrich et al. 1991) and attention restoration theory (ART; Kaplan and Kaplan 1989; Kaplan 1995). The biophilia hypothesis puts forward the notion that humans have an innate tendency to affiliate with the natural world as a result of our biocultural evolution (Kellert 1997). Experiencing this affiliation with nature can fulfill important psychological needs and improve well-being (Kellert 1997). Meanwhile, the SRT emphasizes that natural environments reduce stress by eliciting positive emotional states and lowering physiological arousal. The theory argues that these outcomes are a product of humans' evolutionary past that has resulted in predisposed responses to cues (e.g., vegetation) that once signaled better survival (Ulrich 1983; Ulrich et al. 1991). The ART posits that natural environments can restore the depletion of directed attention, a cognitive resource that is typically depleted in urban environments (Kaplan and Kaplan 1989; Kaplan 1995). The theories are considered complementary rather than contradictory to each other (Berto 2014; Bratman et al. 2012).

In support of these theories, studies have consistently shown that exposure to nature exerts positive effects on emotion and stress across a diverse range of natural settings (for reviews, see Berto 2014; McMahan and Estes 2015; Mygind et al. 2019). The relationship between nature exposure and improved emotional well-being has been found in both correlational (e.g., Bertram and Rehdanz 2015; White et al. 2013), and experimental studies (e.g., Berman et al. 2008; Hartig et al. 1991). For example, a 50-min walk in a nature grassland park decreased anxiety and negative affect compared to a walk along a busy main street (Bratman et al. 2015). A meta-analysis conducted by McMahan and Estes (2015) reported that nature exposure had a moderate effect size on positive affect $(r=0.31)$ and a smaller but still significant effect size on negative affect $(r=-0.12)$. Moreover, compared to urban environments, natural environments lower stress levels in self-report data (e.g., Bratman et al. 2015), physiological indicators like cardiovascular activity, salivary cortisol levels, and skin conductance levels (e.g., Annerstedt et al. 2013; Park et al. 2010; Valtchanov and Ellard 2010), and neurological measures (e.g., Kim et al. 2010).

Nature-based interventions such as garden visits have shown efficacy in promoting well-being in healthcare (Ulrich 1984, 2002). However, such interventions are difficult to implement due to movement restrictions that limit access to parks and other natural environments (Slater et al. 2020). Nature exposure in VR offers a feasible alternative that is appealing to the young population who tend to prefer digital media to spending leisure time outdoors (Pergams and Zaradic 2006). Moreover, it is particularly suitable for the senior population who should avoid going out due to their bio-psychosocial vulnerabilities during the pandemic (Banerjee 2020).

\subsection{Virtual nature}

Past research has examined how viewing computer-mediated forms of nature through slide shows of images (e.g., Berman et al. 2008; Gladwell et al. 2012) or videos (e.g., Mayer et al. 2009; van den Berg et al. 2003) affect physio-psychological processes. For example, heart rate variability increased significantly following the viewing of nature images compared to urban images (Gladwell et al. 2012), and better mood has been found after watching video recordings of a walk through a forest compared to a walk through a street with houses and shops (van den Berg et al. 2003). The purposes of these studies were to examine the effects of actual nature in well-controlled experimental settings, avoiding confounding variables that are difficult to control in field studies. In contrast, our study focused on nature experiences in VR which is much more engaging and immersive than other computer-mediated forms.

Only a handful of studies have examined the effects of natural environments in immersive VR with a head-mounted display. Valtchanov et al. (2010) found that after completing a mentally stressful task, participants who freely explored a virtual forest via a wireless mouse reported improved affect and reduced physiological and self-reported stress, compared to those who watched a slideshow of abstract paintings. In another study, Valtchanov and Ellard (2010) again exposed participants to a mental stressor task before letting 
them freely explore one of three conditions via a wireless mouse: a virtual island with nature sounds, a virtual urban center with city noise, or a geometric environment that did not feature any accompanying sounds except participants' virtual footsteps. Participants in the nature condition displayed improved affect and decreased self-reported and physiological stress levels compared to those in the other two conditions. Using $360^{\circ}$ video recordings of actual natural and urban environments, Yu et al. (2018) found that participants reported more positive psychological outcomes following the nature VR, while they reported more negative psychological outcomes following the urban VR.

The above studies all used VR technologies that are outdated. In addition, they mainly asked participants to either passively view or use a mouse to navigate nature scenes. Our study used the current VR technology which allowed participants to actually walk in the physical world to control their navigation in the VR. In addition, we are the first to measure the effects of virtual nature on both young adults and senior citizens, increasing the validity of our findings. Finally, previous studies did not examine the underlying mechanism of why virtual natural environments improve emotional states, while our study tested the mediating role of nature connectedness to uncover why virtual nature could improve well-being.

\subsection{The role of nature connectedness}

Nature connectedness refers to one's subjective sense of feeling connected to the natural world. It has been proposed as the reason why nature exposure leads to better mood (Kellert 1997; Mayer et al. 2009). Researchers have viewed nature connectedness as a stable trait-like characteristic as well as a state-level variable. Considered as a trait, nature connectedness has been shown to predict the amount of time spent in natural environments (Cheng and Monroe 2012; Nisbet et al. 2009), hedonic well-being (Capaldi et al. 2014), eudaimonic well-being (Pritchard et al. 2020), and pro-environmental attitudes (Davis et al. 2009; Hoot and Friedman 2011). Considered as a state-level variable, nature connectedness has been found to vary with nature exposure (e.g., Mayer et al. 2009; Weinstein et al. 2009; Wyles et al. 2017). For example, participants' nature connectedness was increased after viewing pictures of nature scenes compared to urban scenes (Weinstein et al. 2009). Walking in a natural environment or watching a nature video increased connectedness to nature and positive affect, compared to a corresponding urban one (Mayer et al. 2009). Nature connectedness was also found to vary according to the type of natural exposure-with higher nature connectedness reported after visits to natural environments with national designated status, compared to those without such a status (Wyles et al. 2017).
While past research has shown nature exposure may affect nature connectedness, no study has examined how virtual natural environments may affect connectedness to actual nature. Following existing research, we hypothesized that virtual nature would increase connectedness to actual nature. However, it is possible that virtual natural environments may not have an effect, since the nature in VR is composed using computer-generated graphics and simulations, which differs from replicas of real nature in pictures and videos.

\section{Present research}

The present research examined the effects of virtual nature on affect and stress. It further examined if the effects on affect were due to improved connectedness to actual nature. We first conducted a pilot study to ensure that our virtual nature and urban scenes were comparable in terms of presence, complexity and openness. Then, we conducted two studies, one with young adults (Study 1) and one with senior citizens (Study 2). In both studies, we used a within-subject design where each participant experienced the nature and urban scene on two separate days respectively. We collected participants' self-report and cardiovascular responses. All study protocols were approved by the University ethics committee (IRB-2018-05-053-01), and informed consent was obtained from all participants.

\subsection{Virtual environments}

We developed a nature and urban VR environment using the Unity platform (version 2017.2.0f3). In the nature environment, participants walked along a path between trees in a forest with the sound of light wind, while in the urban environment, participants walked along a path between buildings in a downtown area with the sound of white noise (see Fig. 1). Demo videos of the VR scenes are available online-nature condition: https://www.youtube.com/ watch? $v=$ Ywo3Jbuh8fg; urban condition: https://www. youtube.com/watch? $\mathrm{v}=58 \mathrm{cxs} \times 5-9 \mathrm{qI}$. Both environments were devoid of features that were found to influence emotional well-being, including humans, animals, water, bird sounds, and traffic (Grahn and Stigsdotter 2010; Ratcliffe et al. 2013). We also kept the features and movement in the two environments as consistent as possible. For example, in both environments, participants saw the same blue sky color. They could only walk straight along a path with the same length and width, and they were told that the scene took place in the early morning.

Participants experienced both environments by wearing HTC's VIVE Pro head-mounted device with full auditory and visual immersion. Given that VR may induce symptoms resembling motion sickness (Rebenitsch and 


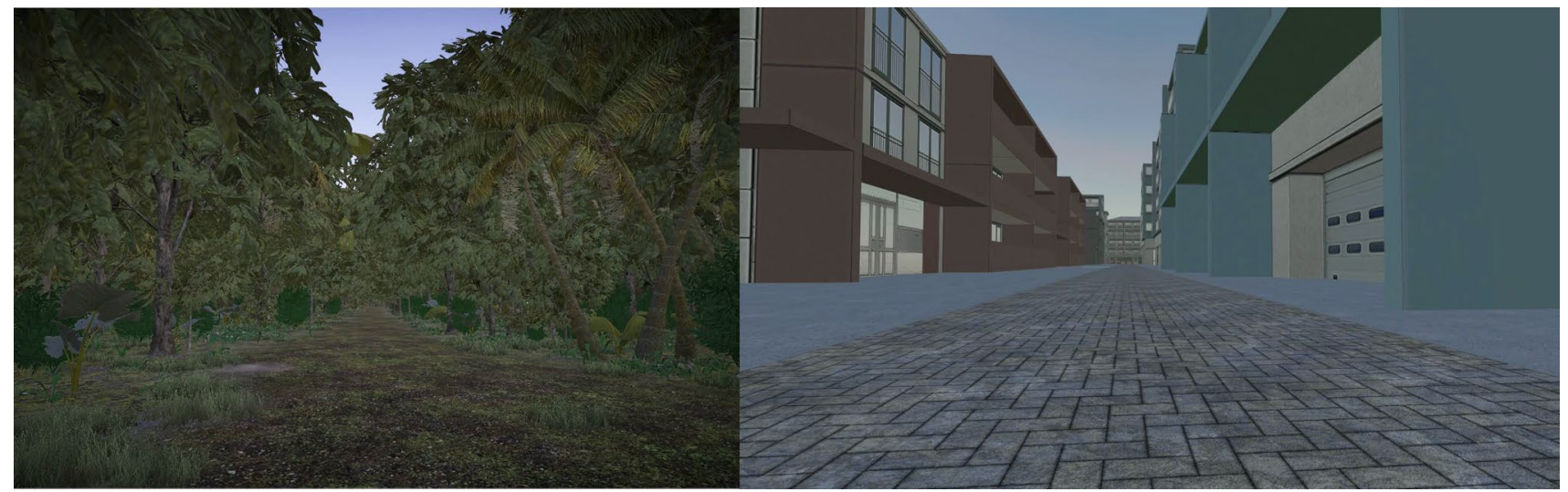

Fig. 1 Screen capture of nature condition (left) and urban condition (right)

Owen 2016), and the synchronization of users' body movement and their visual senses can reduce motion sickness (Llorach et al. 2014; Ng et al. 2019), we developed a program to track the movement of the two wireless controllers so that participants can move the controllers up and down to step forward in VR. For young adults, they walked on the spot while holding onto fixed handle bars with controllers attached to their legs via knee pads (see Fig. 2). In Study 2, the majority of our senior participants had difficulty walking. Therefore, all participants used their hands to move the controllers up and down, while remaining seated (see Fig. 2). In both studies, an experimenter first demonstrated the action required (walking on the spot in Study 1; moving hands up and down in Study 2) for participants to imitate. Participants gave verbal consent that they understood the action required, before the experimenter put on the VR headset. Participants were reminded that they could inform the experimenter at any point in time to end the experiment should they feel uncomfortable. An empty room with a grid path on the floor was

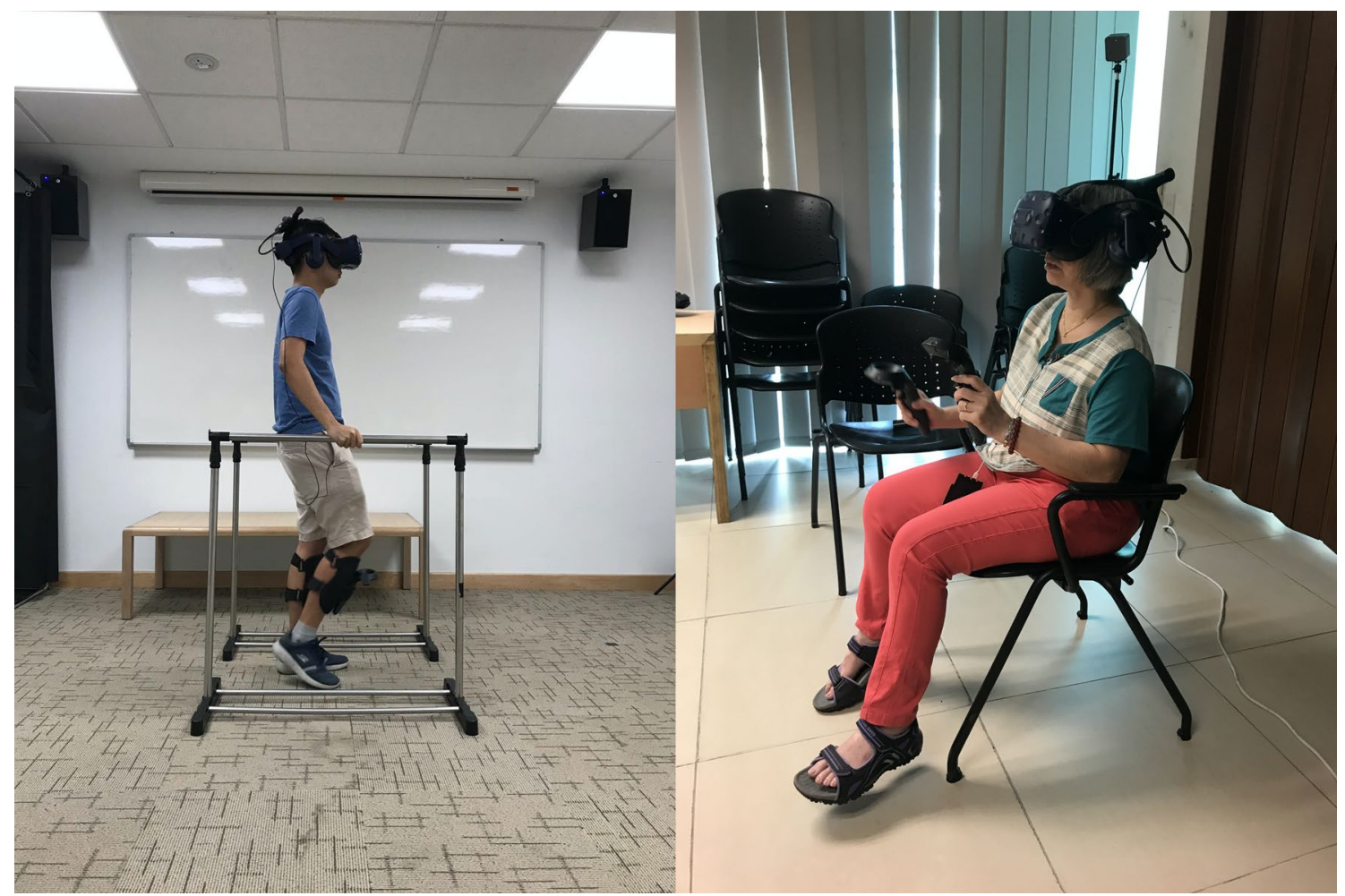

Fig. 2 Walking on the spot while holding onto fixed handlebars for young adults in Study 1 (left) and moving hands up and down for senior citizens in Study 2 (right) 
developed for participants to practice walking before they experienced the actual experimental environments.

\section{Pilot study}

A within-subject design was employed with participants experiencing both condition (nature vs. urban). We measured and compared participants' sense of presence and perceived complexity, openness, and interest of the virtual nature and urban environments. We expected that these variables will be comparable in both environments.

\subsection{Participants and procedures}

Twelve undergraduate students were recruited from a large university in Singapore (females $=6$, age: mean $=22.6$, $\mathrm{SD}=1.3$ ) for the pilot study. Participants were paid $\mathrm{S} \$ 30$ for their participation. They came to two laboratory sessions, with one or two days in between. In each session, participants experienced walking in either the virtual nature or urban environment for $4 \mathrm{~min}$, and completed a survey assessing their perceptions of the environment afterward. The order of VR conditions was counter-balanced across participants.

\subsection{Measures}

We used the 14-item igroup presence questionnaire (IPQ; Schubert et al. 2001) to measure the degree of presence in our VR environments. The IPQ consists of three subscales-spatial presence ( $\alpha=0.51$; e.g., "I felt present in the virtual space"; 1 = fully disagree, $7=$ fully agree), involvement ( $\alpha=0.72$; e.g., "I was not aware of my real environment"; $1=$ fully disagree, $7=$ fully agree), experienced realism $(\alpha=0.74$; e.g., "How real did the virtual world seem to you?"; $1=$ completely real, $7=$ not real at all), and an additional general item measuring a sense of "being there" ( $1=$ fully disagree, 7 =fully agree $)$.
Following Lindal and Hartig (2013), participants were asked to rate the VR environment on an 11-point scale for the degree of complexity $(1=$ simple, $11=$ complex $)$, and sense of being enclosed $(1=$ enclosed, $11=$ open $)$. An additional item on interest was also included $(1=$ boring, $11=$ interesting).

\subsection{Results}

Paired samples $t$ tests revealed no differences between the nature and urban environment for spatial presence, involvement, experienced realism, sense of "being there," perceived complexity, enclosure, and interest (all $p>0.15$ ). This suggests that the nature and urban VR environments were comparable on these key variables that assess various qualities of environments. Descriptive statistics are reported in Table 1.

\section{Study 1}

In this study, we recruited young adults and used a withinsubject design with two within-subject factors-condition (nature vs. urban) and time (for self-report measures: preVR vs. post-VR; for cardiovascular activity: baseline vs. VR task). We hypothesized that the nature condition increases positive affect (H1) and decreases negative affect (H2) compared to the urban condition. We further hypothesized that the relationship between nature exposure and positive affect will be mediated by nature connectedness (H3), and similarly that the relationship between nature exposure and negative affect will be mediated by nature connectedness (H4). In addition, we expected that the nature condition would be associated with a lower level of stress measured by cardiovascular activity compared to the urban condition (H5).

\subsection{Participants and procedures}

Based on the effect size of $r=0.26$ between exposure to simulated nature and positive affect in a meta-analysis study
Table 1 Descriptive statistics for dependent variables in pilot study

\begin{tabular}{llll}
\hline & $\begin{array}{l}\text { Nature } \\
\text { Mean (SD) }\end{array}$ & $\begin{array}{l}\text { Urban } \\
\text { Mean (SD) }\end{array}$ & Mean difference, 95\% CI, $p$, Cohen's $d$ \\
\hline Spatial presence & $4.15(0.93)$ & $4.68(0.87)$ & $-0.53[-1.30,0.23], p=0.15, d=-0.44$ \\
Involvement & $3.94(1.55)$ & $4.00(1.11)$ & $-0.06[-1.45,1.32], p=0.92, d=-0.03$ \\
Experienced realism & $3.52(1.15)$ & $3.54(1.22)$ & $-0.02[-1.00,0.96], p=0.96, d=-0.01$ \\
"Being there" & $4.17(1.64)$ & $4.50(1.62)$ & $-0.33[-1.61,0.95], p=0.58, d=-0.17$ \\
Complexity & $5.50(3.03)$ & $5.75(2.56)$ & $-0.25[-2.55,2.05], p=0.82, d=-0.07$ \\
Enclosure & $6.25(3.67)$ & $6.92(2.94)$ & $-0.67[-3.94,2.61], p=0.66, d=-0.13$ \\
Interest & $8.00(3.64)$ & $8.08(2.58)$ & $-0.08[-2.57,2.41], p=0.94, d=-0.02$ \\
\hline
\end{tabular}

Spatial presence, involvement, experienced realism and "being there" were measured on a 7-point scale. Complexity, enclosure, and interest were measured on an 11-point scale 
(McMahan and Estes 2015), a power analysis performed with G*Power 3.1 (Faul et al. 2009) for alpha $=0.05$ and power $=0.80$ indicated a sample size estimate of $n=22$ for a within-subject comparison. A total of 30 undergraduate students from a large university in Singapore (females $=21$; age: mean $=20.5, \mathrm{SD}=1.5$ ) participated in exchange for course credits. Participants were told that the study was interested in examining perception in VR. About half of the participants $(56.7 \%)$ had never tried VR with a headmounted device prior to the experiment.

Participants experienced the nature and urban environments with one week in-between, and the order was counter-balanced. During each session, participants completed a pre-test survey, a VR task, and a post-test survey. Cardiovascular activity-commonly used in previous studies as a physiological measure of stress (Haluza et al. 2014; Mygind et al. 2019) —was measured continuously with a portable electrocardiogram (ECG) device from BITalino (https://bital ino.com/en/) with disposable electrodes attached under participants' right and left collarbones, and lower left ribcage at a sampling rate of $1000 \mathrm{~Hz}$. The use of ECG measurements has been shown to be a valid reflection of participants' physiological states in virtual environments (Guger et al. 2004). From the ECG recordings, heart rate and heart rate variability were extracted. During the VR task, participants first walked in the virtual practice room for two minutes and then were transported into the target condition for a five-minute walk. We chose a five-minute duration because past research has shown that five-minute viewing of nature scenes is sufficient to induce positive physiological change (Brown et al. 2013; Gladwell et al. 2012).

\subsection{Measures}

\subsubsection{Positive and negative affect}

The positive and negative affect schedule (PANAS; Watson et al. 1988) was used to examine affect. The scale consists of ten items that measure positive affect (e.g., interested, excited; pre-test $\alpha=0.85$, post-test $\alpha=0.90$ ) and another ten items that measure negative affect (e.g., upset, hostile; pre-test $\alpha=0.89$, post-test $\alpha=0.92$ ). Participants indicated the extent they felt each emotion on a 5-point Likert scale $(1=$ very slightly or not at all, $5=$ extremely).

\subsubsection{Nature connectedness}

The connectedness to nature scale (CNS; Mayer and Frantz 2004; Mayer et al. 2009) measures the extent that an individual feels connected to the physical natural world. We used the 13-item state version that assesses state level nature connectedness (pre-test $\alpha=0.89$, post-test $\alpha=0.91$ ). Sample items are "Right now, I feel as though I belong to the earth just as much as it belongs to me," "Right now, I am feeling deeply aware of how my actions affect the natural world," and "Right now, I feel that all inhabitants of earth, human and nonhuman, share a common life force." Participants indicated their extent of agreement with each item on a 7 -point Likert scale $(1=$ strongly disagree, $7=$ strongly agree).

\subsubsection{Cardiovascular activity}

Using customized algorithms generated with the Python programming software (Bizzego et al. 2019; Gabrieli et al. 2020), ECG data were first preprocessed with the application of one high-pass filter and one low-pass filter to clear noise in the signal. $\mathrm{R}$ peaks were then detected and used to determine the inter-beat interval (IBI) - the time between two successive R peaks (Task Force of the European Society of Cardiology and North American Society of Pacing and Electrophysiology 1996). Heart rate as measured by IBI has been used in previous studies examining the effects of nature exposure on physiological response, with a higher IBI reflecting lower stress levels (Park et al. 2010; Ulrich et al. 1991). From IBI, the root mean square of successive differences (RMSSD) was computed. RMSSD is a commonly used time-domain measure of heart rate variability that reflects parasympathetic activation (Task Force of the European Society of Cardiology and North American Society of Pacing and Electrophysiology 1996). The parasympathetic branch of the autonomic nervous system regulates relaxation and restoration of the human body (Andreassi 2010). A higher RMSSD corresponds to a calmer state (Delaney and Brodie 2000).

\subsubsection{Prior VR experience, discomfort, and demographics}

We asked participants to indicate if they had any prior VR experience before the study $(0=$ no, $1=y e s)$, and their age and gender at the end of the study. An additional item was included in the post-test survey asking participants to rate their level of discomfort from $1=$ very slightly or not at all, to $5=$ extremely. None of the participants reported feeling unwell after the VR tasks, and the ratings of post-VR discomfort was low (nature: $M=1.43, \mathrm{SD}=0.73$; urban: $M=1.57, \mathrm{SD}=0.77)$.

\subsection{Results}

Shapiro-Wilk tests for normality showed that the data for positive affect and nature connectedness were normally distributed, but the data for negative affect was not normally distributed. We conducted a 2 (time: pre-VR vs. postVR) $\times 2$ (condition: nature vs. urban) repeated measures analysis of variance (ANOVA) for positive affect and nature 
connectedness. Planned paired $t$ tests were then run to test the simple effects of time in each condition. For negative affect, we performed the nonparametric Friedman's test with follow-up Wilcoxon signed rank tests to examine the effect of time in each condition. In addition, we tested if there was any effect of prior VR experience by including this variable as a between-subject factor in a mixed factorial ANOVA for each of the aforementioned variables. No main or interaction effects were found for prior VR experience (all $p>0.05$; further details provided in Online Resource 1).

\subsubsection{Positive affect}

For positive affect, there was no main effect of time, $F(1$, 29) $=0.77, p=0.39, \eta_{\mathrm{p}}{ }^{2}=0.03$, and no main effect of condition, $F(1,29)=2.01, p=0.17, \eta_{\mathrm{p}}^{2}=0.06$. This was qualified by a significant time-by-condition interaction, $F(1$, 29) $=5.74, p=0.02, \eta_{\mathrm{p}}{ }^{2}=0.17$. In support of Hypothesis 1 , there were no significant changes in positive affect after the nature condition, but positive affect significantly decreased following the urban condition (see Table 2).

\subsubsection{Negative affect}

Friedman's test indicated that there were significant differences in negative affect for conditions at the two time points, $\chi^{2}(3)=17.01, p=0.001$. As shown in Table 2, Wilcoxon tests showed that negative affect significantly decreased in the nature condition (pre-VR median $=1.30$, post-VR median $=1.10$ ), while it did not significantly change in the urban condition (pre-VR median $=1.45$, post-VR median $=1.20$ ). Thus, Hypothesis 2 is supported.

\subsubsection{Nature connectedness}

There was a main effect of time, $F(1,29)=6.92, p=0.01$, $\eta_{\mathrm{p}}{ }^{2}=0.19$, and condition, $F(1,29)=10.91, p=0.003$, $\eta_{\mathrm{p}}{ }^{2}=0.27$, for nature connectedness. This was qualified by a significant time-by-condition interaction, $F(1,29)=12.85$, $p=0.001, \eta_{\mathrm{p}}{ }^{2}=0.31$. As predicted, nature connectedness was significantly greater after the nature condition but did not change following the urban condition (see Table 2).

\subsubsection{Mediation of nature connectedness}

To test if nature connectedness mediated the association between condition and positive affect, we conducted a twocondition within-participant statistical mediation analysis with 10,000 bootstraps using the MEMORE (MEdiation and MOderation analysis for REpeated measures design) macro in SPSS (Montoya and Hayes 2017). Compared to the casual steps approach to mediation analysis that rely on a series of tests (Baron and Kenny 1986; Judd et al. 2001), MEMORE uses a path-analytic approach to estimate the two pathways from IV to DV-direct and indirect (Hayes 2013; Montoya and Hayes 2017). The total effect of IV on DV (i.e., result from a simple regression of IV on DV) is the sum of direct and indirect effects, and does not need to be statistically significant in order for mediation to be tested (Hayes 2009; Shrout and Bolger 2002). Mediation is assessed by a single test of the indirect effect (Hayes and Scharkow 2013) — confidence intervals (CI) that do not contain zero imply that mediation has taken place. We examined the direct and indirect pathways from condition (IV) to changes in positive affect (DV), as measured by post-test score minus pre-test score. The change in nature connectedness, measured as post-test score minus pre-test score, served as the potential mediator. Condition significantly predicted change in nature connectedness, $b=0.60, t(29)=3.58, p=0.001,95 \%$ confidence intervals, CI 0.26, 0.94. However, the indirect effect failed to reach statistical significance $(b=0.19$, bootstrapped $\mathrm{SE}=0.12$, bootstrapped $95 \%$ confidence intervals, CI $-0.09,0.42$ ), suggesting that nature connectedness did not mediate the relationship between condition and positive affect. Therefore, Hypothesis 3 was not supported. The same analysis was repeated for negative affect. Results of
Table 2 Descriptive statistics for Study 1 self-report measures as a function of time and condition

\begin{tabular}{|c|c|c|c|}
\hline & \multicolumn{2}{|l|}{ Mean (SD) } & \multirow{2}{*}{$\begin{array}{l}\text { Simple effects } \\
\text { Test statistic, } p \text {, effect size }\end{array}$} \\
\hline & Pre-VR & Post-VR & \\
\hline \multicolumn{4}{|l|}{ Nature } \\
\hline Positive affect & $2.60(0.71)$ & $2.68(0.86)$ & $t(29)=0.79, p=0.44, d=0.14$ \\
\hline Negative affect & $1.54(0.58)$ & $1.32(0.54)$ & $Z=-2.73, p=0.01, r=-0.35$ \\
\hline Nature connectedness & $4.27(1.03)$ & $4.83(1.05)$ & $t(29)=3.91, p<0.001, d=0.71$ \\
\hline \multicolumn{4}{|l|}{ Urban } \\
\hline Positive affect & $2.59(0.56)$ & $2.38(0.69)$ & $t(29)=-2.29, p=0.03, d=-0.42$ \\
\hline Negative affect & $1.59(0.63)$ & $1.43(0.53)$ & $Z=-1.74, p=0.08, r=-0.23$ \\
\hline Nature connectedness & $4.12(0.96)$ & $4.08(1.07)$ & $t(29)=-0.36, p=0.72, d=-0.07$ \\
\hline
\end{tabular}

The simple effect of time is reported for each row. Results from paired $t$ tests are reported for positive affect and nature connectedness. Results from Wilcoxon signed ranks tests are reported for negative affect 
the mediation analysis are shown in Fig. 3. The indirect effect was statistically significant $(b=-0.18$, bootstrapped $\mathrm{SE}=0.09$, bootstrapped $95 \%$ confidence intervals, $\mathrm{CI}-0.37$, -0.02 ), suggesting that nature connectedness mediated the relationship between condition and negative affect. Therefore, Hypothesis 4 was supported.

\subsubsection{Cardiovascular activity}

After screening for the quality of ECG signal, data from 28 out of 30 participants were accepted for analyses. IBI and RMSSD were extracted for every $10 \mathrm{~s}$, with $5 \mathrm{~s}$ overlapping with the next data point. Baseline IBI was computed as the mean IBI during the $1 \mathrm{~min}$ that participants spent in the practice room before being transported to the VR condition. VR task IBI was computed as the mean IBI over the 5 min that participants walked in the experimental condition. Shapiro-Wilk tests for normality showed that the data were not normally distributed. Thus, natural log transformation was applied to IBI and RMSSD before analysis. Tests for normality on the log-transformed data showed normal distribution.

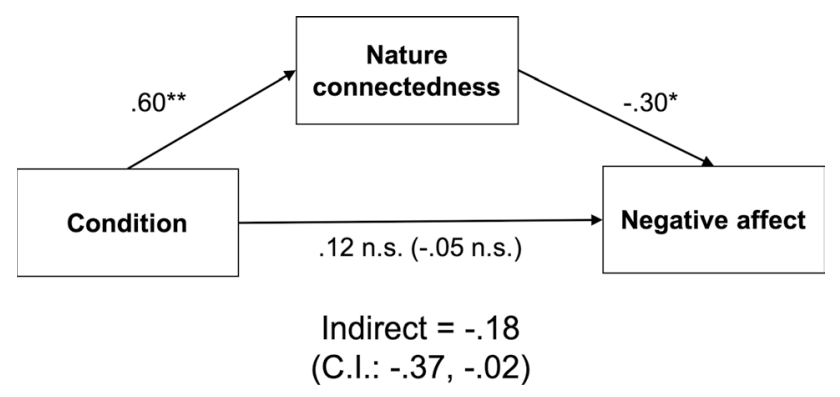

Fig. 3 Mediation analysis testing whether the effect of condition on change in negative affect (post-test minus pre-test) is mediated by change in nature connectedness (post-test minus pre-test). Unstandardized path coefficients are shown. The direct effect reported in parentheses represents the association between condition and change in negative affect when the mediator is excluded. ${ }^{*} p<0.05$, $* * p<0.01, * * * p<0.001$
To examine the effects on heart rate, we ran a 2 (time: baseline vs. VR task) X 2 (condition: nature vs. urban) repeated measures ANOVA with IBI as the dependent variable. There was no main effect of time $(F(1,27)=3.32$, $\left.p=0.08, \eta_{\mathrm{p}}{ }^{2}=0.11\right)$ and no main effect of condition $(F(1$, $\left.27)=0.00, p=0.99, \eta_{\mathrm{p}}{ }^{2}=0.00\right)$. This was qualified by a significant time-by-condition interaction, $F(1,27)=7.93$, $p=0.01, \eta_{\mathrm{p}}{ }^{2}=0.23$. As shown in Table 3, IBI significantly increased from baseline during the nature condition, suggesting greater relaxation, but had no significant changes during the urban condition.

To examine the effects on heart rate variability, a similar 2 $\mathrm{X} 2$ repeated measures ANOVA was conducted for RMSSD. There was no main effect of time, $F(1,27)=0.10, p=0.76$, $\eta_{\mathrm{p}}{ }^{2}=0.00$, and no main effect of condition, $F(1,27)=0.96$, $p=0.34, \eta_{\mathrm{p}}{ }^{2}=0.03$. The time-by-condition was also not significant, $F(1,27)=1.90, p=0.18, \eta_{\mathrm{p}}^{2}=0.07$. Although the change in RMSSD did not reach conventional statistical significance, RMSSD increased in the nature condition which suggests less stress, while it decreased in the urban condition which suggests more stress (see Table 3).

To further examine differences by condition in cardiovascular activity, we plotted the change in IBI (calculated as IBI at a given time point during the 5-min experimental condition minus baseline IBI) between the nature and urban conditions at every 10-s window, with $5 \mathrm{~s}$ overlapping with the next data point. This was done using the original data that were not log-transformed. As shown in Fig. 4, the line representing the nature condition lies above the line that represents the urban condition over the whole timeframe. This suggests a lower heart rate, and thus calmer physiological state, throughout the nature condition compared to the urban condition. The same was done for RMSSD, and results are shown in Fig. 5. The line representing the nature condition is for the most part, lying above the line representing the urban condition - thereby suggesting greater parasympathetic activation, corresponding to a calmer state, during the nature condition compared to the urban condition. Overall, the results for cardiovascular activity supported Hypothesis 5 .
Table 3 Descriptive statistics for cardiovascular indicators in Study 1 as a function of time and condition

\begin{tabular}{|c|c|c|c|}
\hline & \multicolumn{2}{|l|}{ Mean (SD) } & \multirow{2}{*}{$\begin{array}{l}\text { Simple effects } \\
\text { Test statistic, } p \text {, effect size }\end{array}$} \\
\hline & Baseline & VR task & \\
\hline \multicolumn{4}{|l|}{ Nature } \\
\hline IBI & $-0.397(0.111)$ & $-0.380(0.118)$ & $t(27)=2.69, p=0.01, d=0.50$ \\
\hline RMSSD & $-4.017(0.554)$ & $-3.992(0.576)$ & $t(27)=0.61, p=0.54, d=0.11$ \\
\hline \multicolumn{4}{|l|}{ Urban } \\
\hline IBI & $-0.389(0.096)$ & $-0.388(0.095)$ & $t(27)=0.27, p=0.79, d=0.04$ \\
\hline RMSSD & $-4.061(0.539)$ & $-4.109(0.441)$ & $t(27)=-1.01, p=0.32, d=-0.19$ \\
\hline
\end{tabular}

IBI and RMSSD went through natural log transformation. The simple effect of time is reported for each row based on results from paired $t$ tests 


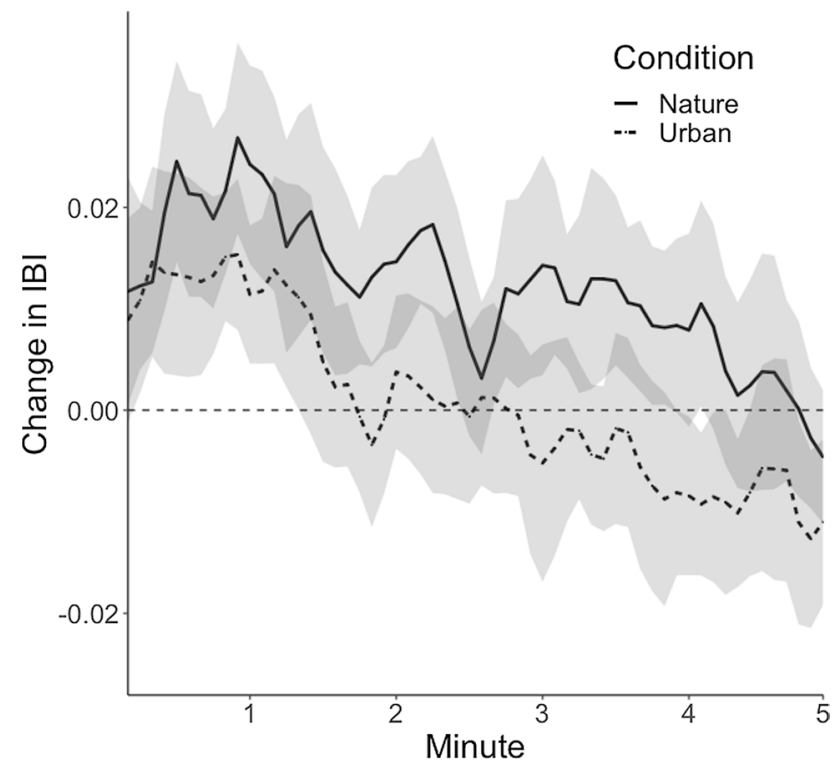

Fig. 4 Change in IBI by experimental condition with $95 \%$ confidence intervals. Change in IBI was computed as IBI at the given time minus baseline IBI

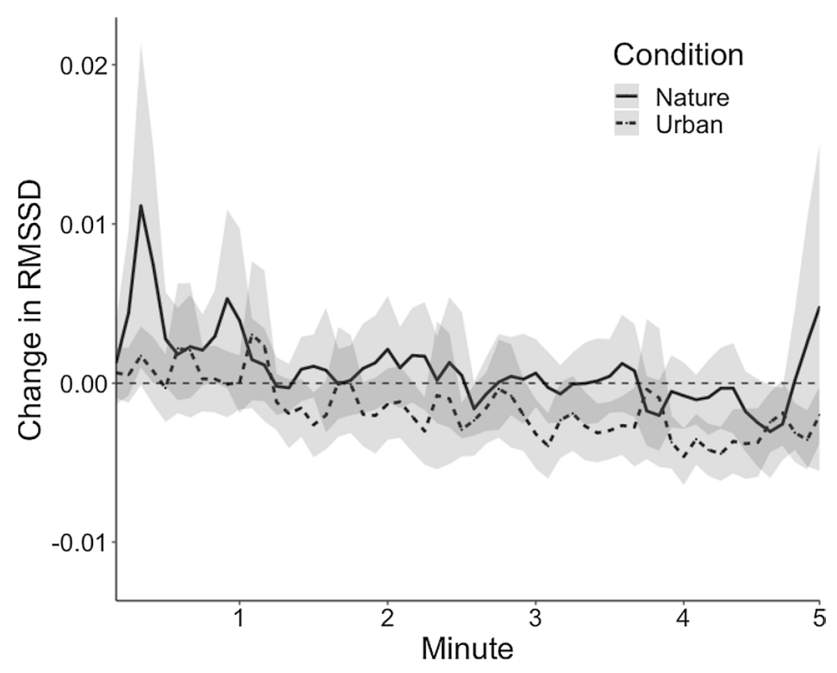

Fig. 5 Change in RMSSD by experimental condition with 95\% confidence intervals. Change in RMSSD was computed as RMSSD at the given time minus baseline RMSSD

\section{Study 2}

Study 1 examined the effects of virtual nature among young adults. In Study 2, we aimed to investigate the effects of virtual natural environments on senior citizens, an understudied population that may greatly enjoy the benefits of VR to reduce their barrier of experiencing nature. A within-subject design was employed with two within-subject factors-condition (nature vs. urban) and time (for self-report measures: pre-VR vs. post-VR; for cardiovascular activity: baseline vs. VR task). We hypothesized that compared to the urban condition, the nature condition increases positive affect (H6), which is mediated by nature connectedness (H7). It is also hypothesized that nature condition is associated with a lower level of stress reflected by self-report (H8) and cardiovascular activity (H9) compared to urban condition.

\subsection{Participants and procedures}

As mentioned in Sect. 4.1, a power analysis indicated a sample size estimate of $n=22$ for a within-subject comparison. A total of 26 seniors were recruited from a senior citizens' community center in Singapore. However, six participants dropped out after the first session due to unforeseen reasons that were unrelated to the current study (e.g., sudden hospitalization), resulting in a final sample of 20 participants (females $=18$; age: mean $=72.7, \mathrm{SD}=8.8$ ) who were paid $\mathrm{S} \$ 30$ for their participation. None of the participants had tried VR with a head-mounted device prior to the experiment.

Participants experienced the nature and urban condition with one week in-between, and the order was counter-balanced. All measures were administered verbally by a female experimenter, and participants answered questions verbally because many of them were illiterate. Participants followed the same procedure as in Study 1, except that they experienced the VR practice room for $1 \mathrm{~min}$ (instead of $2 \mathrm{~min}$ in Study 1) and experienced the target VR environment for 3 min (instead of 5 min in Study 1).

\subsection{Measures}

We simplified the measures in Study 1 because many of the participants had difficulty understanding the items.

\subsubsection{Positive affect}

To assess positive affect, participants were asked to rate how happy they felt at the current moment on a 5-point scale ( $1=$ very slightly or not at all; $5=$ extremely).

\subsubsection{Nature connectedness}

To assess nature connectedness, participants were asked to rate how connected to nature they felt at the current moment on a 5 -point scale $(1=$ very slightly or not at all; $5=$ extremely). 


\subsubsection{Self-reported stress}

To assess stress, participants were asked to rate how stressed they felt at the current moment on a 5 -point scale $(1=$ very slightly or not at all; $5=$ extremely).

\subsubsection{Cardiovascular activity}

Cardiovascular responses were recorded using an ECG as in Study 1.

\subsubsection{Prior VR experience, discomfort, and demographics}

Participants were asked if they had any prior VR experience before the study $(0=$ no, $1=$ yes $)$, and their age and gender at the end of the study. After the VR task, participants were asked if they felt unwell. None of the participants reported feeling unwell after the VR task.

\subsection{Results}

Shapiro-Wilk tests for normality showed that the data for positive emotion, nature connectedness, and self-report stress were not normally distributed. Thus, we performed the nonparametric Friedman's test with follow-up Wilcoxon signed rank tests to examine the effect of time in each condition. Descriptive statistics are reported in Table 4.

\subsubsection{Positive affect}

Friedman's test indicated that there were significant differences in positive affect for conditions at the two time points, $\chi^{2}(3)=11.98, p=0.01$. As shown in Table 4, Wilcoxon tests showed that positive affect significantly increased in the nature condition (pre-VR median $=3.00$, post-VR median $=4.00$ ). In contrast, positive affect did not significantly change in the urban condition (pre-VR median $=3.50$, post-VR median $=3.00$ ). Thus, Hypothesis 6 was supported.

\subsubsection{Nature connectedness}

Friedman's test indicated that there were significant differences in nature connectedness between conditions at the two time points, $\chi^{2}(3)=19.06, p<0.001$. As shown in Table 4, Wilcoxon tests showed that nature connectedness significantly increased in the nature condition (preVR median $=3.00$, post-VR median $=4.00)$, whereas it significantly decreased in the urban condition (pre-VR median $=4.00$, post-VR median $=3.00$ ).

\subsubsection{Mediation of nature connectedness}

A two-condition within-participant statistical mediation analysis with 10,000 bootstraps was conducted using MEMORE (Montoya and Hayes 2017). Direct and indirect pathways from condition to changes in positive affect (posttest score minus pre-test score) were examined, with the change in nature connectedness (post-test score minus pretest score) as the potential mediator. Results of the mediation analysis are shown in Fig. 6. The indirect effect was significant $(b=0.67$, bootstrapped $\mathrm{SE}=0.32$, bootstrapped $95 \%$ confidence intervals, CI 0.13, 1.37), suggesting that nature connectedness mediated the relationship between condition and positive affect. Thus, Hypothesis 7 was supported.

\subsubsection{Self-reported stress}

Friedman's test indicated that there were no significant differences in stress for conditions at the two time points, $\chi^{2}(3)=3.27, p=0.35$. Wilcoxon tests showed that there were no significant changes in stress in either the nature condition (pre-VR median $=2.00$, post-VR median $=1.00$ ), or urban condition (pre-VR median $=2.00$, post-VR median $=1.50$ ). Thus, Hypothesis 8 was not supported. Nonetheless, although the change in stress did not reach conventional statistical significance, stress decreased slightly in the nature condition, while it increased slightly in the urban condition (see Table 4).
Table 4 Descriptive statistics for Study 2 dependent variables as a function of time and condition

\begin{tabular}{|c|c|c|c|}
\hline & \multicolumn{2}{|l|}{ Mean (SD) } & \multirow{2}{*}{$\begin{array}{l}\text { Simple effects } \\
\text { Test statistic, } p \text {, effect size }\end{array}$} \\
\hline & Pre-VR & Post-VR & \\
\hline \multicolumn{4}{|l|}{ Nature } \\
\hline Positive affect & $3.40(0.68)$ & $4.00(0.80)$ & $Z=3.21, p=0.001, r=0.51$ \\
\hline Nature connectedness & $2.95(1.10)$ & $3.90(0.97)$ & $Z=3.58, p<0.001, r=0.57$ \\
\hline Self-report stress & $2.00(0.80)$ & $1.65(0.81)$ & $Z=1.81, p=0.07, r=-0.29$ \\
\hline \multicolumn{4}{|l|}{ Urban } \\
\hline Positive affect & $3.60(0.82)$ & $3.25(1.16)$ & $Z=1.64, p=0.10, r=-0.26$ \\
\hline Nature connectedness & $3.40(1.23)$ & $2.80(1.54)$ & $Z=1.98, p=0.048, r=-0.31$ \\
\hline Self-report stress & $1.80(0.77)$ & $1.85(0.99)$ & $Z=0.38, p=0.71, r=0.06$ \\
\hline
\end{tabular}

The simple effect of time is reported for each row based on Wilcoxon signed rank tests 


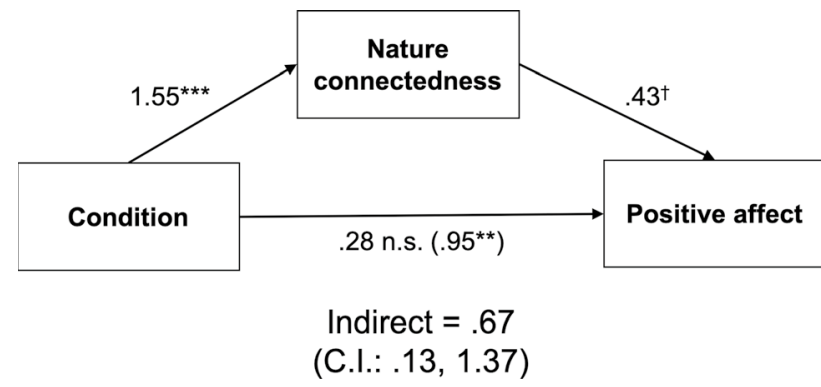

Fig. 6 Mediation analysis testing whether the effect of condition on change in positive affect (post-test minus pre-test) is mediated by change in nature connectedness (post-test minus pre-test). Unstandardized path coefficients are shown. The direct effect reported in parentheses represents the association between condition and change in positive affect when the mediator is excluded. ${ }^{\dagger} p<0.1,{ }^{*} p<0.05$, $* * p<.01, * * * p<0.001$

\subsubsection{Cardiovascular activity}

After screening the ECG data, $\mathrm{R}$ peaks could not be extracted from the data of six participants due to irregularities. Irregularities in ECG data of older adults are common (e.g., Ferreira et al. 2014), and may be due to relatively prevalent medical conditions like diabetes and hypertension (Abe et al. 1996). The remaining sample was too small to draw any meaningful conclusions. Thus, no further analyses were conducted on cardiovascular responses and Hypothesis 9 could not be tested.

\section{General discussion}

VR technologies have become increasingly affordable and accessible to everyday households, and offer a safe and practical solution to promote well-being via immersive nature exposure in these challenging times. In this research, we examined the effects of virtual nature among young adults and senior citizens. Across both samples, we found that a walk in a virtual natural environment resulted in an improved emotional state, and that this effect was mediated by an enhanced sense of nature connectedness. Our study unveils the underlying mechanism of why virtual natural environments can improve emotional well-being. It provides strong empirical evidence of virtual nature by using a within-subject design with two distinct samples to mitigate the problems associated with causal heterogeneity (Bullock et al. 2010). To the best of our knowledge, our study is the first to examine the effects of a virtual natural environment on a senior sample. This contributes to the scant empirical evidence of nature's positive effects on non-Western and older populations (Haluza et al. 2014; Kondo et al. 2018). Furthermore, results from Study 1 showed that nature VR was associated with lower stress and greater relaxation measured with heart rate and heart rate variability. Similarly in Study 2, seniors reported slightly lower stress after the nature VR although this did not reach conventional statistical significance.

Our Study 1 showed that negative affect decreased, while positive affect did not change following the nature condition, whereas our Study 2 showed that positive affect increased (negative affect was not measured) after the nature condition. There could be several explanations for the inconsistencies. Firstly, Study 1's participants were young adults (mean age $=20.5$ ), while Study 2 consisted of older adults (mean age $=72.7$ ), and age has been shown to be a moderator on the effect of nature exposure such that larger effect sizes for positive affect were found among older participants (McMahan and Estes 2015). This corresponds with the current findings that show a much stronger effect of virtual nature on positive affect and nature connectedness among seniors (Study 2) compared to young adults (Study 1). However, no conclusions can be drawn as this may be due to the different measurements used in both samples. In addition, the length of the VR immersion and method of movement also differed between the young adults and senior citizens in order to accommodate different levels of attention and mobility capability. In another within-subject study that involved a 50 min walk in a nature and urban setting, positive affect did not change for the nature walk but significantly decreased for the urban group, while negative affect decreased across both settings with a significantly larger decrease in the nature compared to urban walk (Bratman et al. 2015), corresponding to the findings of Study 1. Furthermore, in Study 1, the mediation of enhanced nature connectedness was significant only for the relationship between condition and negative affect but not for the relationship between condition and positive affect, while in Study 2, the mediation of enhanced nature connectedness was significant for the relationship between condition and positive affect. This differs from previous findings which found mediational support of nature connectedness for positive affect only, but not negative affect (Mayer et al. 2009). This highlights the nuanced effects that nature has on positive and negative affect respectively. Future research is needed to investigate the specific direction of change and further examine how virtual nature may affect youth and seniors differently.

The present findings on physiological indicators of stress align with past findings that show lower stress levels in nature compared to urban settings (Brown et al. 2013; Lee et al. 2011; Park et al. 2010). Specifically, Study 1 showed that heart rate was higher in the urban condition compared to nature condition, replicating past studies that similarly showed greater heart rate in actual urban environments compared to nature ones (Lee et al. 2011; Park et al. 2010). As for parasympathetic activation based on heart rate variability, Study 1 showed that RMSSD increased slightly during 
the nature condition but decreased slightly during the urban condition, although neither of these changes reached conventional statistical significance. This ties in with a study conducted by Brown et al. (2013) in which RMSSD did not change while viewing a slideshow of nature scenes but decreased when viewing a slideshow of built scenes. This suggests that nature can buffer against the stress elicited by urban environments.

Diminished nature experiences are not only detrimental to health and well-being, but can also exacerbate the growing disconnect that urban populations feel toward nature (Soga and Gaston 2016). The excessive use of electronics among young people has already been associated with reduced time spent outdoors in nature (Larson et al. 2018; Pergams and Zaradic 2006), a problem that may be magnified with schools and workplaces shifting online. Past researchers have raised the concern that virtual nature may devalue and even replace actual nature (Levi and Kocher 1999; Litleskare et al. 2020). They warn that people may adapt too much to virtual nature and become accustomed to the loss of real nature exposure (Kahn et al. 2008; Kahn et al. 2009). With the widespread growth of VR systems, there is an urgency to address the positive and negative outcomes that virtual nature may have on people's relationship with their environments. In our study, results showed that participants were more connected to actual nature after their virtual nature exposure. Given that higher nature connectedness predicts more time spent in nature (Cheng and Monroe 2012; Nisbet et al. 2009), our study suggests that rather than diminishing the need to experience real nature, virtual nature may lead to stronger motivation to spend time in real nature. Future research needs to further distinguish between connectedness to real vs. virtual nature, as well as examine if virtual nature exposure would translate into more real nature experiences.

VR fidelity refers to the degree to which the VR environment replicates the real-life environment (Alessi 1988; Liu et al. 2008). The VR scenes in our study have only a moderate degree of fidelity because they were designed conservatively to exclude elements like animals or people. Current VR technology enables the development of high-fidelity natural environments. For example, dynamic natural processes such as light diffusion through plant foliage and reflection of light on water can be achieved (Depledge et al. 2011). High audio fidelity can be developed through the synchronization of stereo recordings and visual cues such as the motion of trees swaying along with the sound of wind and leaves rustling (Lindquist et al. 2020). High movement fidelity can be achieved through precise head tracking and locomotion techniques that best mimic real-life walking (Nilsson et al. 2016; Templeman et al. 1999). While high fidelity can enhance positive outcomes like presence and perceived realism in VR (Lindquist et al. 2020; McMahan et al. 2012), there are still many sensory cues present in real natural environments that cannot yet be replicated in VR (Depledge et al. 2011). For example, air temperature, wind velocity, and thermal heat are important to psychological responses in natural environments (Park et al. 2011), but they are not available in VR. It is possible that high-fidelity virtual natural environments with increased biodiversity, water features, and bird sounds would create high fascination and result in even stronger effects on nature connectedness, affect, and stress. Future research should find ways of incorporating other sensory cues into VR experiences and examine the role of fidelity in computer-generated natural environments.

\subsection{Practical implications}

Our findings have important applications. Lockdowns and quarantines have resulted in social isolation and severely restricted opportunities to visit nature. Virtual natural environments provide a source of nature exposure that can alleviate psychological distress. The relative ease of setting up VR systems make it a viable solution for many healthcare settings like care homes and quarantine facilities. Moreover, low-cost systems like the Google Cardboard (https:// arvr.google.com/cardboard/) also enable users to experience virtual nature using their smartphones from their homes.

While not a primary objective of the present research, the studies highlight the potential benefits of VR as a complementary tool in urban planning and environmental psychological research. VR offers methodological benefits such as providing high degrees of experimental control while simultaneously providing an experience that is closer to real life compared to pictures or videos (Blascovich et al. 2002). The current findings suggest that virtual nature evokes similar effects as real nature. While caution should be exercised when extrapolating the findings of virtual environments that are computer-generated to real-world settings, VR may nonetheless serve as a methodological tool in preliminary investigations, for example, studying the psychophysiological responses to vertical greenery on a row of high-rise buildings (Chan et al. 2021).

\subsection{Limitations}

There are several limitations in our study. First, the duration of the VR immersion was short (5 min for Study 1; 3 min for Study 2). The current study is not able to address questions of how long the positive effects will last, whether a longer immersion would result in different effects, or whether the effects are subjected to habituation if the virtual natural environment is experienced over repeated occasions. Second, research has shown that VR has a tendency to induce symptoms resembling motion sickness like nausea, dizziness, and other general discomforts (Rebenitsch and Owen 2016). However, none of our participants reported 
feeling uncomfortable. One possible reason is that participants' navigation and speed were controlled by themselves through walking (Study 1) or moving their hands (Study 2) such that their body movement synchronized with their visual senses - a key feature which research shows can reduce motion sickness (Llorach et al. 2014; $\mathrm{Ng}$ et al. 2019). Nonetheless, motion sickness is an important limitation of VR which future research should seek to mitigate. Third, participants in our Study 1 (young adults) and Study 2 (seniors) did not complete the same measures due to psychological and physical limitations of the seniors. Effect sizes between Study 1 and Study 2 thus cannot be directly compared. Future research may replicate Study 2 with a younger population, or directly compare samples from different age groups using the same experimental conditions and measures to further examine the validity of our findings. The current experimental results with seniors would also benefit from replication using a larger sample size with well-validated measures. Finally, the current study has only examined one type of nature setting (i.e., forest). Future studies may examine if other types of nature settings (e.g., mountains, oceans, deserts) will evoke the same effects on nature connectedness and affect, and whether a similar mechanism is at play.

\section{Conclusion}

The COVID-19 pandemic has disrupted everyday living, leaving many in a state of psychological distress. While nature offers solace to promote mental health, the pandemic has reduced access to it. VR offers a safe alternative to experience nature. This study showed that a short walk in a virtual forest improved emotional state among young adults and senior citizens through the enhancement of nature connectedness. It underscores the potential of nature exposure through VR to increase nature connectedness, which in turn can improve psychological well-being during the pandemic.

Supplementary Information The online version contains supplementary material available at https://doi.org/10.1007/s10055-021-00604-4.

Authors' contributions All authors made substantial contributions to the work, and have read and approved of this version of the article.

Funding This work was supported by Singapore Ministry of Education AcRF Tier 1 Grant RG83/17 and NTU ARISE Inaugural Grant Call 2017 Seed Funding awarded to the second author.

Availability of data and materials The data analyzed in this study is publicly available at the first author's institutional data repository (doi masked to remove author information).

Code availability Not applicable.

\section{Declarations}

Conflict of interest All authors declare no potential conflicts of interest with respect to the research, authorship, and/or publication of this article.

\section{References}

Abe S, Yoshizawa M, Nakanishi N, Yazawa T, Yokota K, Honda M, Sloman G (1996) Electrocardiographic abnormalities in patients receiving hemodialysis. Am Heart J 131:1137-1144. https://doi.org/10.1016/S0002-8703(96)90088-5

Alessi SM (1988) Fidelity in the design of instructional simulations. J Comput Based Instr 15:40-47

Andreassi JL (2010) The nervous system and measurement of its activity. In: Andreassi JL (ed) Psychophysiology: human behavior and physiological response. Psychology Press, New York. https://doi.org/10.4324/9780203880340

Annerstedt $M$ et al (2013) Inducing physiological stress recovery with sounds of nature in a virtual reality forest-results from a pilot study. Physiol Behav 118:240-250. https://doi.org/10. 1016/j.physbeh.2013.05.023

Banerjee D (2020) The impact of Covid-19 pandemic on elderly mental health. Int J Geriatr Psychiatry 35:1466-1467. https:// doi.org/10.1002/gps.5320

Baron RM, Kenny DA (1986) The moderator-mediator variable distinction in social psychological research: conceptual, strategic, and statistical considerations. J Pers Soc Psychol 51:11731182. https://doi.org/10.1037//0022-3514.51.6.1173

Berman MG, Jonides J, Kaplan S (2008) The cognitive benefits of interacting with nature. Psychol Sci 19:1207-1212. https://doi. org/10.1111/j.1467-9280.2008.02225.x

Berto R (2014) The role of nature in coping with psycho-physiological stress: a literature review on restorativeness. Behav Sci 4:394-409. https://doi.org/10.3390/bs4040394

Bertram C, Rehdanz K (2015) The role of urban green space for human well-being. Ecol Econ 120:139-152. https://doi.org/ 10.1016/j.ecolecon.2015.10.013

Bizzego A, Battisti A, Gabrieli G, Esposito G, Furlanello C (2019) pyphysio: A physiological signal processing library for data science approaches in physiology. SoftwareX 10:Article 100287. https://doi.org/10.1016/j.softx.2019.100287

Blascovich J, Loomis J, Beall AC, Swinth KR, Hoyt CL, Bailenson JN (2002) Immersive virtual environment technology as a methodological tool for social psychology. Psychol Inq 13:103-124. https://doi.org/10.1207/S15327965PLI1302_01

Bourdillon N, Yazdani S, Schmitt L, Millet GP (2020) Effects of COVID-19 lockdown on heart rate variability. PLoS ONE 15:e0242303. https://doi.org/10.1371/journal.pone.0242303

Bratman GN, Hamilton JP, Daily GC (2012) The impacts of nature experience on human cognitive function and mental health. Ann N Y Acad Sci 1249:118-136. https://doi.org/10.1111/j. 1749-6632.2011.06400.x

Bratman GN, Daily GC, Levy BJ, Gross JJ (2015) The benefits of nature experience: Improved affect and cognition. Landsc Urban Plan 138:41-50. https://doi.org/10.1016/j.landurbplan. 2015.02.005

Brown DK, Barton JL, Gladwell VF (2013) Viewing nature scenes positively affects recovery of autonomic function following acute-mental stress. Environ Sci Technol 47:5562-5569. https://doi.org/10.1021/es305019p 
Bullock JG, Green DP, Ha SE (2010) Yes, but what's the mechanism? (don't expect an easy answer). J Pers Soc Psychol 98:550-558. https://doi.org/10.1037/a0018933

Capaldi CA, Dopko RL, Zelenski JM (2014) The relationship between nature connectedness and happiness: a meta-analysis. Front Psychol 5:Article 976. https://doi.org/10.3389/fpsyg.2014.00976

Chan SHM, Qiu L, Esposito G, Mai KP (2021) Vertical greenery buffers against stress: evidence from psychophysiological responses in virtual reality. Landsc Urban Plan 213:104127. https://doi.org/ 10.1016/j.landurbplan.2021.104127

Cheng JC-H, Monroe MC (2012) Connection to nature: children's affective attitude toward nature. Environ Behav 44:31-49. https:// doi.org/10.1177/0013916510385082

Cherniack EP (2011) Not just fun and games: applications of virtual reality in the identification and rehabilitation of cognitive disorders of the elderly. Disabil Rehabil Assist Technol 6:283-289. https://doi.org/10.3109/17483107.2010.542570

Davis JL, Green JD, Reed A (2009) Interdependence with the environment: commitment, interconnectedness, and environmental behavior. J Environ Psychol 29:173-180. https://doi.org/10. 1016/j.jenvp.2008.11.001

Delaney JPA, Brodie DA (2000) Effects of short-term psychological stress on the time and frequency domains of heart-rate variability. Percept Mot Skills 91:515-524. https://doi.org/10.2466/pms. 2000.91.2.515

Depledge MH, Stone RJ, Bird WJ (2011) Can natural and virtual environments be used to promote improved human health and wellbeing? Environ Sci Technol 45:4660-4665. https://doi.org/ $10.1021 / \mathrm{es} 103907 \mathrm{~m}$

Faul F, Erdfelder E, Buchner A, Lang AG (2009) Statistical power analyses using $\mathrm{G}^{*}$ Power 3.1: tests for correlation and regression analyses. Behav Res Methods 41:1149-1160. https://doi.org/10. 3758/brm.41.4.1149

Ferreira E, Ferreira D, Kim S, Siirtola P, Röning J, Forlizzi JF, Dey AK (2014) Assessing real-time cognitive load based on psychophysiological measures for younger and older adults. In: Proceedings of the 2014 IEEE symposium on computational intelligence, Cognitive Algorithms, Mind, and Brain (CCMB), Orlando, FL, USA, 9-12 December 2014. Orlando, FL, USA, pp 39-48. https://doi.org/10.1109/CCMB.2014.7020692

Gabrieli G, Azhari A, Esposito G (2020) PySiology: a python package for physiological feature extraction. In: Esposito A, FaundezZanuy M, Morabito FC, Pasero E (eds) Neural approaches to dynamics of signal exchanges. Springer Singapore, Singapore, pp 395-402. https://doi.org/10.1007/978-981-13-8950-4_35

Gladwell VF et al (2012) The effects of views of nature on autonomic control. Eur J Appl Physiol 112:3379-3386. https://doi.org/10. 1007/s00421-012-2318-8

Grahn P, Stigsdotter UK (2010) The relation between perceived sensory dimensions of urban green space and stress restoration. Landsc Urban Plan 94:264-275. https://doi.org/10.1016/j.landu rbplan.2009.10.012

Guger C et al (2004) Heart-rate variability and event-related ECG in virtual environments. Paper presented at the [Paper presentation]. Presence 2004: 7th Annual International Workshop on Presence, Valencia, Spain, October 13-15

Haluza D, Schönbauer R, Cervinka R (2014) Green perspectives for public health: a narrative review on the physiological effects of experiencing outdoor nature. Int J Environ Res Public Health 11:5445-5461. https://doi.org/10.3390/ijerph110505445

Hartig T, Mang M, Evans GW (1991) Restorative effects of natural environment experiences. Environ Behav 23:3-26. https://doi. org/10.1177/0013916591231001

Hayes AF (2009) Beyond Baron and Kenny: statistical mediation analysis in the new millennium. Commun Monogr 76:408-420. https://doi.org/10.1080/03637750903310360
Hayes AF (2013) Introduction to mediation, moderation, and conditional process analysis: a regression-based approach. Guilford Press, New York

Hayes AF, Scharkow M (2013) The relative trustworthiness of inferential tests of the indirect effect in statistical mediation analysis: does method really matter? Psychol Sci 24:1918-1927. https://doi.org/10.1177/0956797613480187

Hoot RE, Friedman H (2011) Connectedness and environmental behavior: sense of interconnectedness and pro-environmental behavior. Int J Transpers Stud 30:89-100

Huygelier H, Schraepen B, van Ee R, Vanden Abeele V, Gillebert CR (2019) Acceptance of immersive head-mounted virtual reality in older adults. Sci Rep 9:4519. https://doi.org/10.1038/ s41598-019-41200-6

Judd CM, Kenny DA, McClelland GH (2001) Estimating and testing mediation and moderation in within-subject designs. Psychol Methods 6:115-134. https://doi.org/10.1037/1082-989X.6.2. 115

Kahn PH et al (2008) A plasma display window? The shifting baseline problem in a technologically mediated natural world. J Environ Psychol 28:192-199. https://doi.org/10.1016/j.jenvp.2007.10.008

Kahn PH, Severson RL, Ruckert JH (2009) The human relation with nature and technological nature. Curr Dir Psychol Sci 18:37-42. https://doi.org/10.1111/j.1467-8721.2009.01602.x

Kaplan S (1995) The restorative benefits of nature: toward an integrative framework. J Environ Psychol 15:169-182. https://doi.org/ 10.1016/0272-4944(95)90001-2

Kaplan R, Kaplan S (1989) The experience of nature: a psychological perspective. Cambridge University Press, New York

Kellert SR (1997) Kinship to mastery: Biophilia in human evolution and development. Island Press, Washington

Kellert SR, Wilson EO (1993) The Biophilia hypothesis. Island Press, Washington

Kharroubi S, Saleh F (2020) Are lockdown measures effective against COVID-19? Front Public Health 8:Article 549692. https://doi. org/10.3389/fpubh.2020.549692

Kim TH et al (2010) Human brain activation in response to visual stimulation with rural and urban scenery pictures: a functional magnetic resonance imaging study. Sci Total Environ 408:2600 2607. https://doi.org/10.1016/j.scitotenv.2010.02.025

Kondo MC, Fluehr JM, McKeon T, Branas CC (2018) Urban green space and its impact on human health. Int J Environ Res Public Health 15:Article 445. https://doi.org/10.3390/ijerph15030445

Kothgassner OD, Goreis A, Kafka JX, Hlavacs H, Beutl L, KryspinExner I, Felnhofer A (2018) Agency and gender influence older adults' presence-related experiences in an interactive virtual environment. Cyberpsychol Behav Soc Netw 21:318-324. https://doi.org/10.1089/cyber.2017.0691

Lang B (2021) [Updated] VR headsets on steam hit record high three months running. Road to VR. https://www.roadtovr.com/month ly-connected-headsets-steam-3-million-march-2021/

Larson LR, Szczytko R, Bowers EP, Stephens LE, Stevenson KT, Floyd MF (2018) Outdoor time, screen time, and connection to nature: troubling trends among rural youth? Environ Behav 51:966-991. https://doi.org/10.1177/0013916518806686

Lee J, Park BJ, Tsunetsugu Y, Ohira T, Kagawa T, Miyazaki Y (2011) Effect of forest bathing on physiological and psychological responses in young Japanese male subjects. Public Health 125:93-100. https://doi.org/10.1016/j.puhe.2010.09.005

Lee H-S, Dean D, Baxter T, Griffith T, Park S (2021) Deterioration of mental health despite successful control of the COVID-19 pandemic in South Korea. Psychiatry Res 295:Article 113570. https://doi.org/10.1016/j.psychres.2020.113570

Levi D, Kocher S (1999) Virtual nature: the future effects of information technology on our relationship to nature. Environ Behav 31:203-226. https://doi.org/10.1177/00139169921972065 
Li Z et al (2020) Vicarious traumatization in the general public, members, and non-members of medical teams aiding in COVID-19 control. Brain Behav Immun 88:916-919. https://doi.org/10. 1016/j.bbi.2020.03.007

Lindal PJ, Hartig T (2013) Architectural variation, building height, and the restorative quality of urban residential streetscapes. J Environ Psychol 33:26-36. https://doi.org/10.1016/j.jenvp.2012.09.003

Lindquist M, Maxim B, Proctor J, Dolins F (2020) The effect of audio fidelity and virtual reality on the perception of virtual greenspace. Landsc Urban Plan 202:103884. https://doi.org/10.1016/j. landurbplan.2020.103884

Liszio S, Masuch M (2019) Interactive immersive virtual environments cause relaxation and enhance resistance to acute stress. Annu Rev Cyberther Telemed 17:65-71

Litleskare S, MacIntyre TE, Calogiuri G (2020) Enable, reconnect and augment: a new ERA of virtual nature research and application. Int J Environ Res Public Health 17:1738. https://doi.org/10.3390/ ijerph17051738

Liu D, Macchiarella ND, Vincenzi DA (2008) Simulation fidelity. In: Hancock PA, Vincenzi DA, Wise JA, Mouloua M (eds) Human factors in simulation and training. CRC Press, pp 61-73

Llorach G, Evans A, Blat J (2014) Simulator sickness and presence using HMDs: comparing use of a game controller and a position estimation system. In: Proceedings of the 20th ACM symposium on virtual reality software and technology, Edinburgh, Scotland, 11-13 November 2014. ACM Digital Library, Edinburgh, Scotland, pp 137-140. https://doi.org/10.1145/2671015.2671120

Matamala-Gomez M, Maselli A, Malighetti C, Realdon O, Mantovani F, Riva G (2021) Virtual body ownership illusions for mental health: a narrative review. J Clin Med. https://doi.org/10.3390/ jem10010139

Mayer FS, Frantz CM (2004) The connectedness to nature scale: a measure of individuals' feeling in community with nature. J Environ Psychol 24:503-515. https://doi.org/10.1016/j.jenvp. 2004.10.001

Mayer FS, Frantz CM, Bruehlman-Senecal E, Dolliver K (2009) Why is nature beneficial? The role of connectedness to nature. Environ Behav 41:607-643. https://doi.org/10.1177/0013916508319745

McMahan EA, Estes D (2015) The effect of contact with natural environments on positive and negative affect: a meta-analysis. J Posit Psychol 10:507-519. https://doi.org/10.1080/17439760. 2014.994224

McMahan RP, Bowman DA, Zielinski DJ, Brady RB (2012) Evaluating display fidelity and interaction fidelity in a virtual reality game. IEEE Trans vis Comput Graph 18:626-633. https://doi.org/10. 1109/tvcg.2012.43

Micarelli A, Viziano A, Micarelli B, Augimeri I, Alessandrini M (2019) Vestibular rehabilitation in older adults with and without mild cognitive impairment: effects of virtual reality using a headmounted display. Arch Gerontol Geriatr 83:246-256. https://doi. org/10.1016/j.archger.2019.05.008

Moccia L et al (2020) Affective temperament, attachment style, and the psychological impact of the COVID-19 outbreak: an early report on the Italian general population. Brain Behav Immun 87:75-79. https://doi.org/10.1016/j.bbi.2020.04.048

Montoya AK, Hayes AF (2017) Two-condition within-participant statistical mediation analysis: a path-analytic framework. Psychol Methods 22:6-27. https://doi.org/10.1037/met0000086

Mygind L, Kjeldsted E, Hartmeyer R, Mygind E, Stevenson MP, Quintana DS, Bentsen P (2019) Effects of public green space on acute psychophysiological stress response: a systematic review and meta-analysis of the experimental and quasi-experimental evidence. Environ Behav 53:184-226. https://doi.org/10.1177/ 0013916519873376

Ng AKT, Chan LKY, Lau HYK (2019) A study of cybersickness and sensory conflict theory using a motion-coupled virtual reality system. Displays 61:Article 101922. https://doi.org/10.1016/j. displa.2019.08.004

Nilsson NC, Serafin S, Nordahl R (2016) Walking in place through virtual worlds. In: Kurosu M (ed) Human-computer interaction. Interaction platforms and techniques. HCI 2016. Lecture notes in computer science, vol 9732. Springer, pp 37-48. https://doi.org/10.1007/978-3-319-39516-6_4

Nisbet EK, Zelenski JM, Murphy SA (2009) The nature relatedness scale: linking individuals' connection with nature to environmental concern and behavior. Environ Behav 41:715-740. https://doi.org/10.1177/0013916508318748

Optale G et al (2010) Controlling memory impairment in elderly adults using virtual reality memory training: a randomized controlled pilot study. Neurorehabil Neural Repair 24:348-357. https://doi.org/10.1177/1545968309353328

Park BJ, Tsunetsugu Y, Kasetani T, Kagawa T, Miyazaki Y (2010) The physiological effects of Shinrin-yoku (taking in the forest atmosphere or forest bathing): evidence from field experiments in 24 forests across Japan. Environ Health Prev Med 15:18-26. https://doi.org/10.1007/s12199-009-0086-9

Park BJ, Furuya K, Kasetani T, Takayama N, Kagawa T, Miyazaki Y (2011) Relationship between psychological responses and physical environments in forest settings. Landsc Urban Plan 102:24-32. https://doi.org/10.1016/j.landurbplan.2011.03.005

Park MJ, Kim DJ, Lee U, Na EJ, Jeon HJ (2019) A literature overview of Virtual Reality (VR) in treatment of psychiatric disorders: recent advances and limitations. Front Psychiatry 10:Article 505. https://doi.org/10.3389/fpsyt.2019.00505

Pergams ORW, Zaradic PA (2006) Is love of nature in the US becoming love of electronic media? 16-year downtrend in national park visits explained by watching movies, playing video games, internet use, and oil prices. J Environ Manag 80:387393. https://doi.org/10.1016/j.jenvman.2006.02.001

Pouso S, Borja Á, Fleming LE, Gómez-Baggethun E, White MP, Uyarra MC (2021) Contact with blue-green spaces during the COVID-19 pandemic lockdown beneficial for mental health. Sci Total Environ 756:Article 143984. https://doi.org/10. 1016/j.scitotenv.2020.143984

Pritchard A, Richardson M, Sheffield D, McEwan K (2020) The relationship between nature connectedness and eudaimonic well-being: a meta-analysis. J Happiness Stud 21:1145-1167. https://doi.org/10.1007/s10902-019-00118-6

Ratcliffe E, Gatersleben B, Sowden PT (2013) Bird sounds and their contributions to perceived attention restoration and stress recovery. J Environ Psychol 36:221-228. https://doi.org/10. 1016/j.jenvp.2013.08.004

Rebenitsch L, Owen C (2016) Review on cybersickness in applications and visual displays. Virtual Real 20:101-125. https://doi. org/10.1007/s10055-016-0285-9

Riva G et al (2020) COVID feel good-an easy self-help virtual reality protocol to overcome the psychological burden of Coronavirus. Front Psychiatry 11:Article 563319. https://doi.org/10. 3389/fpsyt.2020.563319

Robillard G, Bouchard S, Fournier T, Renaud P (2003) Anxiety and presence during VR immersion: a comparative study of the reactions of phobic and non-phobic participants in therapeutic virtual environments derived from computer games. Cyberpsychol Behav 6:467-476. https://doi.org/10.1089/1094931037 69710497

Rogers S (2018) Why millennials need VR. Forbes. https://www.forbes. com/sites/solrogers/2018/10/23/why-millennials-need-vr/\#7bb9e 7396260

Satariano WA, Guralnik JM, Jackson RJ, Marottoli RA, Phelan EA, Prohaska TR (2012) Mobility and aging: new directions for public health action. Am J Public Health 102:1508-1515. https://doi. org/10.2105/AJPH.2011.300631 
Schubert T, Friedmann F, Regenbrecht H (2001) The experience of presence: factor analytic insights. Presence 10:266-281. https:// doi.org/10.1162/105474601300343603

Shrout PE, Bolger N (2002) Mediation in experimental and nonexperimental studies: new procedures and recommendations. Psychol Methods 7:422-445. https://doi.org/10.1037/1082-989X.7.4.422

Sibley CG et al (2020) Effects of the COVID-19 pandemic and nationwide lockdown on trust, attitudes toward government, and wellbeing. Am Psychol 75:618-630. https://doi.org/10.1037/amp00 00662

Slater M (2018) Immersion and the illusion of presence in virtual reality. Br J Psychol 109:431-433. https://doi.org/10.1111/bjop. 12305

Slater S, Christiana R, Gustat J (2020) Recommendations for keeping parks and green space accessible for mental and physical health during COVID-19 and other pandemics. Prev Chronic Dis 17:e59. https://doi.org/10.5888/pcd17.200204

Soga M, Gaston KJ (2016) Extinction of experience: the loss of human-nature interactions. Front Ecol Environ 14:94-101. https://doi.org/10.1002/fee.1225

Tang B et al (2020) The effectiveness of quarantine and isolation determine the trend of the COVID-19 epidemics in the final phase of the current outbreak in China. Int J Infect Dis 95:288-293. https://doi.org/10.1016/j.ijid.2020.03.018

Task Force of the European Society of Cardiology, North American Society of Pacing and Electrophysiology (1996) Heart rate variability: standards of measurement, physiological interpretation, and clinical use. Circulation 93:1043-1065. https://doi.org/10. 1161/01.CIR.93.5.1043

Templeman JN, Denbrook PS, Sibert LE (1999) Virtual locomotion: walking in place through virtual environments. Presence 8:598617. https://doi.org/10.1162/105474699566512

The Lancet Infectious Diseases (2020) The intersection of COVID-19 and mental health. Lancet Infect Dis 20:1217. https://doi.org/10. 1016/S1473-3099(20)30797-0

Ulrich RS (1983) Aesthetic and affective response to natural environment. In: Altman I, Wohlwill JF (eds) Behavior and the natural environment. Human behavior and environment (advances in theory and research). Springer, Boston, pp 85-125

Ulrich RS (1984) View through a window may influence recovery from surgery. Science 224:420-421. https://doi.org/10.1126/science. 6143402

Ulrich RS, Simons RF, Losito BD, Fiorito E, Miles MA, Zelson M (1991) Stress recovery during exposure to natural and urban environments. J Environ Psychol 11:201-230. https://doi.org/ $10.1016 / \mathrm{S} 0272-4944(05) 80184-7$

Ulrich RS (2002) Health benefits of gardens in hospitals. Paper presented at the Plants for People International Exhibition Floriade 2002, Netherlands. https://www.researchgate.net/publication/ 252307449_Health_Benefits_of_Gardens_in_Hospitals
Valtchanov D, Ellard C (2010) Physiological and affective responses to immersion in virtual reality: effects of nature and urban settings. J Cyber Ther Rehabil 3:359-373

Valtchanov D, Barton KR, Ellard C (2010) Restorative effects of virtual nature settings. Cyberpsychol Behav Soc Netw 13:503-512. https://doi.org/10.1089/cyber.2009.0308

van den Berg AE, Koole SL, van der Wulp NY (2003) Environmental preference and restoration: (how) are they related? J Environ Psychol 23:135-146. https://doi.org/10.1016/S0272-4944(02) 00111-1

Watson D, Clark LA, Tellegen A (1988) Development and validation of brief measures of positive and negative affect: the PANAS scales. J Pers Soc Psychol 54:1063-1070. https://doi.org/10.1037//00223514.54.6.1063

Weinstein N, Przybylski AK, Ryan RM (2009) Can nature make us more caring? Effects of immersion in nature on intrinsic aspirations and generosity. Pers Soc Psychol Bull 35:1315-1329. https://doi.org/10.1177/0146167209341649

Wen C, Albert C, Von Haaren C (2018) The elderly in green spaces: exploring requirements and preferences concerning nature-based recreation. Sustain Cities Soc 38:582-593. https://doi.org/10. 1016/j.scs.2018.01.023

White RG, Van Der Boor C (2020) Impact of the COVID-19 pandemic and initial period of lockdown on the mental health and wellbeing of adults in the UK. Bjpsych Open 6:e90. https://doi.org/ 10.1192/bjo.2020.79

White M, Alcock I, Wheeler BW, Depledge MH (2013) Would you be happier living in a greener urban area? A fixed-effects analysis of panel data. Psychol Sci 24:920-928. https://doi.org/10.1177/ 0956797612464659

White M, Yeo NL, Vassiljev P, Lundstedt R, Wallergård M, Albin M, Lõhmus M (2018) A prescription for "nature"-the potential of using virtual nature in therapeutics. Neuropsychiatr Dis Treat 14:3001-3013. https://doi.org/10.2147/NDT.S179038

Wilson EO (1984) Biophilia. Harvard University Press

Wyles KJ, White MP, Hattam C, Pahl S, King H, Austen M (2017) Are some natural environments more psychologically beneficial than others? The importance of type and quality on connectedness to nature and psychological restoration. Environ Behav 51:111-143. https://doi.org/10.1177/0013916517738312

Yu C-P, Lee H-Y, Luo X-Y (2018) The effect of virtual reality forest and urban environments on physiological and psychological responses. Urban for Urban Green 35:106-114. https://doi.org/ 10.1016/j.ufug.2018.08.013

Publisher's Note Springer Nature remains neutral with regard to jurisdictional claims in published maps and institutional affiliations. 